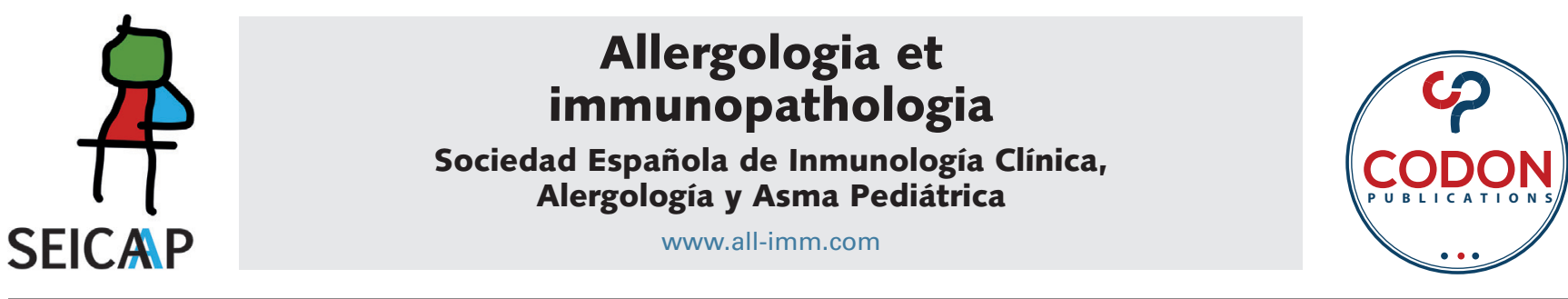

ORIGINAL ARTICLE

\title{
Does Sugammadex Suppress Allergic Inflammation Due to Rocuronium in Animal Model of Rat?
}

\author{
Serdar Yeşiltaşa*, Zeynep Nur Orhon ${ }^{\mathrm{b}}$, Hasan Cakırc, Mahmut Dogrud, Melek Güra Çelik ${ }^{\mathrm{b}}$
}

a Bezmialem Vakıf University Medical Faculty Department of Anesthesiology and Reanimation, Istanbul, Turkey

${ }^{b}$ Medeniyet University Medical Faculty Department of Anesthesiology and Reanimation, Istanbul, Turkey

'Ozel Yasam Hospital, Department of Anesthesiology and Reanimation, Batman, Turkey

${ }^{a}$ Memorial Sisli Hospital, Department of PediatricAllergy-Immunology, Istanbul, Turkey

Received 25 October 2020; Accepted 22 November 2020

Available online 1 May 2021

\section{KEYWORDS \\ Anaphylaxis; \\ inflammation; \\ lung; \\ rat; \\ rocuronium; \\ sugammadex}

\begin{abstract}
Introduction and Objectives: There are a few reports in the literature about the successful use of sugammadex in the treatment of hypersensitivity reactions caused by rocuronium; however, the pathophysiological mechanism is still unknown. This study aims to investigate the changes caused by rocuronium in the lung and the effect of sugammadex on these changes with biochemical, light microscopic and immunohistochemical parameters on a rat model.

Materials and Methods: For the study, 28-male Sprague-Dawley rats were randomly divided, seven of each, into four groups. Group C (control) received only $0.9 \% \mathrm{NaCl}$ without any drug. Group $R$ received rocuronium alone $1 \mathrm{mg} / \mathrm{kg}$. Group $\mathrm{S}$ received sugammadex alone $96 \mathrm{mg} / \mathrm{kg}$. Group RS received rocuronium $1 \mathrm{mg} / \mathrm{kg}$ and sugammadex $96 \mathrm{mg} / \mathrm{kg}$. After $24 \mathrm{~h}$ later, the animals were sacrificed and their tissues were removed. Biochemical (IgE/CRP), light microscopic and immunohistochemical findings were recorded.

Results: Immunoglobulin E and CRP levels, peribronchial, alveolar septal lymphocytic infiltration, thickening of the alveolar membranes and bleeding sites in Group R were significantly higher than all the other groups. In Group RS, while these parameters were significantly lower than that of Group R and Group S, it was significantly higher than that of Group C. Total mast cells and tryptase-positive mast cells counts were significantly higher in Group R than in all other groups. In Group RS, these parameters were statistically lower than that of Group R and Group S, but higher than that of Group C.

Conclusions: This study shows that allergic inflammatory changes due to rocuronium in the lungs of rats are reduced with sugammadex. These results support cases of anaphylaxis due to rocuronium which improved with sugammadex.
\end{abstract}

(c) 2021 Codon Publications. Published by Codon Publications.

${ }^{*}$ Corresponding author: Serdar Yeșiltaș, MD. Department of Anesthesiology and Reanimation, Bezmialem Vakıf University, Adnan Menderes Bulvarı Vatan cd; 34093 - Fatih, Istanbul, Turkey. Email address: syesiltas@bezmialem.edu.tr; drserdaryesiltas@hotmail.com 


\section{Introduction}

Perioperative anaphylactic reactionsare immediate, hypersensitive reactions that are potentially life-threatening resulting from a sudden release of mediators from mast cells and basophiles, due to either immune (IgE or non-IgE mediated) or non-immune mechanisms. Even the frequency of perioperative hypersensitivity reactions ranges from $1 / 358$ to $1 / 18,600 .^{1-3}$ These reactions occur, especially, due to neuromuscular blocking agents (NMBA), induction agents, opioids, latex, antibiotics, and colloid fluids. The NMBA have been reported to account for most of the perioperative hypersensitivity reactions..$^{1,4,5}$ Rocuronium is an aminosteroid non-depolarising NMBA with a rapid to intermediate onset depending on its dose. It is used as bromide salt in general anaesthesia to facilitate endotracheal intubation and as a skeletal muscle relaxant during surgery or mechanical ventilation. ${ }^{6,7}$ Sadleir et al. ${ }^{8}$ reported that rocuronium was the main responsible agent in $56 \%$ of life-threatening anaphylaxis cases developing against non-depolarising NMBAs over a decade in Western Australia.

Sugammadex is a gamma-cyclodextrin used as the first selective NMBA binding agent, designed to bind steroidal non-depolarising NMBA, like rocuronium and vecuronium. By encapsulating rocuronium molecules in plasma and detaching them from the neuromuscular junction, sugammadex rapidly reverses rocuronium-induced, neuromuscular blockade in a main time of under 2 min and eliminates circulating rocuronium molecules via the renal route and prevents their metabolism.9,10 The utility of sugammadex as a selective encapsulating agent for rocuronium has led to speculation that it may be useful in mitigating rocuronium-induced anaphylaxis. Indeed, in line with this expectation, sugammadex has been used in the treatment of anaphylaxis due to rocuronium and improvement has been achieved in various anaphylaxis cases. ${ }^{11-13}$ In contrast, cases of anaphylaxis due to sugammadex have been reported with increased clinical use of sugammadex. ${ }^{14}$ In the study of Min et al., ${ }^{15}$ the frequency of sugammadex-induced hypersensitivity reactions was found to be $0.56 \%$ and $0.21 \%$ for sugammadex $2 \mathrm{mg} / \mathrm{kg}$ and $4 \mathrm{mg} / \mathrm{kg}$, respectively. Apart from rocuronium and sugammadex-induced anaphylaxis, anaphylaxis cases related to rocuronium-sugammadex inclusion complex have been reported in recent years. ${ }^{16,17}$

Mast cells are immune cells residing in connective tissue containing large metachromatic granules and play a central role in inflammatory and immediate allergic reactions such as anaphylaxis. Tryptase is the most abundant mediator stored in the granules of mast cells and it is an indicator of mast cell activation. The effects of rocuronium and sugammadex on mast cells and tryptase in liver and pancreas were investigated in rats. ${ }^{18,19}$ However, its effects on the lung, one of the important organs affected in anaphylaxis, are unknown. We planned to investigate the changes caused by rocuronium in the lung and the effect of sugammadex on these changes with biochemical, light microscopic, and immunohistochemical parameters on a rat model.

\section{Materials and methods}

\section{Animals}

All animals received humancare according to the criteria outlined in the "Guide for the Care and Use of Laboratory Animals" prepared by the National Academy of Sciences and published by the National Institutes of Health. For the study, 28 adult Sprague-Dawley male rats weighing 300-350 g (Yeditepe University Animal Care and Research Unit, Istanbul, Turkey) were housed under constant temperature $\left(21^{\circ} \mathrm{C}\right)$, humidity (50\%-55\%) and photoperiod (12 h light/dark cycle). They had free access to standard rat chow diet.

The study was approved by the Institutional Animal Ethics Committee of the Yeditepe University, Istanbul, Turkey (10.21.2013/ 357).

\section{Study groups}

The animals were divided into four equal groups $(\mathrm{N}=7)$ as follows; control group (Group C) received only $0.9 \% \mathrm{NaCl}$ without any drug, rocuronium (Esmeron; Organon, Istanbul, Turkey) only group (Group R) received rocuronium $1 \mathrm{mg} / \mathrm{kg}$, sugammadex (Bridion; Schering-Plough Corporation, Oss, Netherlands) only group (Group S) received sugammadex $96 \mathrm{mg} / \mathrm{kg}$, and combined group (Group RS) received both rocuronium $1 \mathrm{mg} / \mathrm{kg}$ and $5 \mathrm{~min}$ later, sugammadex $96 \mathrm{mg} / \mathrm{kg}$. All drugs were administered intravenously via the tail vein. Rats receiving rocuronium were ventilated with an Ambu ventilator (PlusMED, Istanbul, Turkey) until resolution of spontaneous ventilation started, and then rats were marked according to their groups and followed in the cage for about $24 \mathrm{~h}$. After $24 \mathrm{~h}$, blood samples were taken from the rats for biochemical assessment and the rats were anesthetised with ketamine $(90 \mathrm{mg} / \mathrm{kg}$ i.p.). Following the anaesthesia, the animals were sacrificed and their lung tissues were removed. The tissue samples were put in the $10 \%$ formaldehyde solution. Blood samples were kept at $-70^{\circ} \mathrm{C}$ until the biochemical analyses were done. Then, immunoglobulin $\mathrm{E}$ (IgE) and C-reactive protein (CRP) levels of those samples were determined. Biochemical, immunohistochemical and light microscopic findings were recorded.

\section{Tissue preparation processes}

The lung tissues excised for light microscopic examinations were processed at the İstanbul Medeniyet University Medical Faculty, Department of Pathology Light Microscopy Laboratory. For that purpose, after the lung tissues were fixed in $10 \%$ neutral buffered formalin, the control process was started. Tissues were kept in the residual alcohol batches $(70 \%, 90 \%, 96 \%$ and $100 \%)$ for $1 \mathrm{~h}$. After the dehydration process, tissues were treated with toluene for 15 min for clearing step. Before the embedding process, tissues were kept in soft paraffin for one night long. The next day, lung tissues were taken out of soft paraffin and they were kept in the liquid paraffin for an hour and then 
they were blocked. $3 \mu \mathrm{m}$-thick (micrometer) sections were excised from these blocks with the help of a Leica RM 2245 cylinder microtome. The excised tissues were stained with haematoxylin and eosin in order to show the characteristics of the lung tissue and they were stained with toluidineblue to show the mast cells.

\section{Biochemical processes}

Serum/plasma samples were centrifugated and kept in $-80^{\circ} \mathrm{C}$ deep-freeze by using eppendorf. During the process, we waited it to be thawed in the room temperature. Elx80 microplate washers and readers and original packaged assay kits were used for rat lgE and CRP tests.

\section{CRP measurement}

ELISA Kit for Rat C-Reactive Protein (Eastbiopharm, China) was used for the study. The test works with the principle of immune sandwich enzyme and a plate covered in anticorpse which are specific to CRP was used. The amount of CRP in samples were calculated as $\mathrm{ng} / \mathrm{ml}$. Assay range: 3 $\mathrm{ng} / \mathrm{ml}-900 \mathrm{ng} / \mathrm{ml}$, assay sensitivity: $1.5 \mathrm{ng} / \mathrm{ml}$.

\section{Immunoglobulin E measurement}

ELISA Kit for Rat Immunoglobulin E (Eastbiopharm, China) was used for the study. The test works with the principle of immune sandwich enzyme and a plate covered in anticorpse which are specific to IgE was used. The amount of IgE in samples were calculated as $\mu \mathrm{g} / \mathrm{ml}$. Assay range: 0.5 $\mathrm{mcg} / \mathrm{ml}-150 \mathrm{mcg} / \mathrm{ml}$, assay sensitivity: $0.25 \mathrm{mcg} / \mathrm{ml}$.

\section{Immunohistochemical examination}

For immunohistochemical examination, $3 \mu$ m-thick (micrometer) sections were excised from the lung tissues and sections were put into water after the deparaffinisation process. The sections were simmered in microwave oven in antigen retrieval for $20 \mathrm{~min}$. The sections were washed with PBS after they were left to cool for 20 min in room temperature. After this step, they were treated with $3 \%$ hydrogen peroxide $\left(\mathrm{H}_{2} \mathrm{O}_{2}\right.$ which was prepared in methanol (Riedel-De Häen 24229) in order to remove the hydrogen peroxide reaction. Upon rinsing them with the distilled water, the sections were washed with PBS $(\mathrm{pH}$ : 7.6). In order to block the non-specific antibody forming cells, $1 \%$ pre-immune rabbit serum (Ultra V Block, LabVision, TA-015-UB) was administered to the sections. Then the sections were incubated for an hour with anti-tryptase rabbit polyclonal antibody (Cat. \#342M-16, Cell Marque, USA) which was diluted in humid chamber at the rate of $1 / 50$. After washing them three times with PBS, sections were kept in the secondary antibody solution (Biotinylated Goat Anti-Rabbit, LabVisionUltraVision Plus Large Volume Detection System Anti-Polyvalent, HRP Kit) for $20 \mathrm{~min}$. The sections that were washed for three times were administered streptavidin peroxidase (Streptavidin Peroxidase, LabVision, TS-015-HR) for $20 \mathrm{~min}$. After washing them three times, the sections were administered chromogen 3-amino-9-ethylcarbazole (LabVision, TA-002$\mathrm{HAC}$ ) for $10 \mathrm{~min}$. After the sections were washed with distilled water, they were administered Mayer haematoxylin solution for $5 \mathrm{~min}$ and then contrast dyeing was applied. The sections that were washed in the stream were taken to the examination by putting a lamella on them and adding Mounting Medium, LabVision, TA-060-UG.

The scoring of cells that showed metachromasia during the toluidine dyeing and tryptase-positive mast cells that were seen in immunohistochemical dyeing was made. Random 8 region was selected with the help of an Olympus CX41 by using the standard ocular grid and the scoring of these mast cells was made.

\section{Statistical analysis}

Statistical analysis was carried out with SPSS 11.0. All the data were stated as mean \pm standard deviation (SD) and the differences between the groups were evaluated with Kruskal-Wallis-variance analysis. By making Bonferroni correction, Mann-Whitney $U$ test was used to compare binary groups. The differences were accepted to be significant if they were $p<0.05$.

\section{Results}

\section{Macroscopic results}

When the thoraxes of the rats were cut with midline incision, haemorrhagic areas in lungs were observed in Group R, Group S and Group RS, particularly in Group R (Figure 1).

\section{Biochemical results}

IgE and CRP levels in Group R were significantly higher than all the other groups. In Group RS, although IgE and CRP levels were significantly lower than that of Group $R$ and Group S, it was significantly higher than that of Group C (Table 1).

\section{Light microscopic results}

\section{Haematoxylin-eosin staining}

Peribronchial and alveolar septal lymphocytic infiltration, thickening of the alveolar membranes and bleeding sites increased significantly in Group $\mathrm{R}$ than the other groups. In Group RS, peribronchial and alveolar septal lymphocytic infiltration, thickening of the alveolar membranes and bleeding sites decreased significantly when compared with Group R and Group S. However, these changes were higher than that of Group C (Figure 2). 


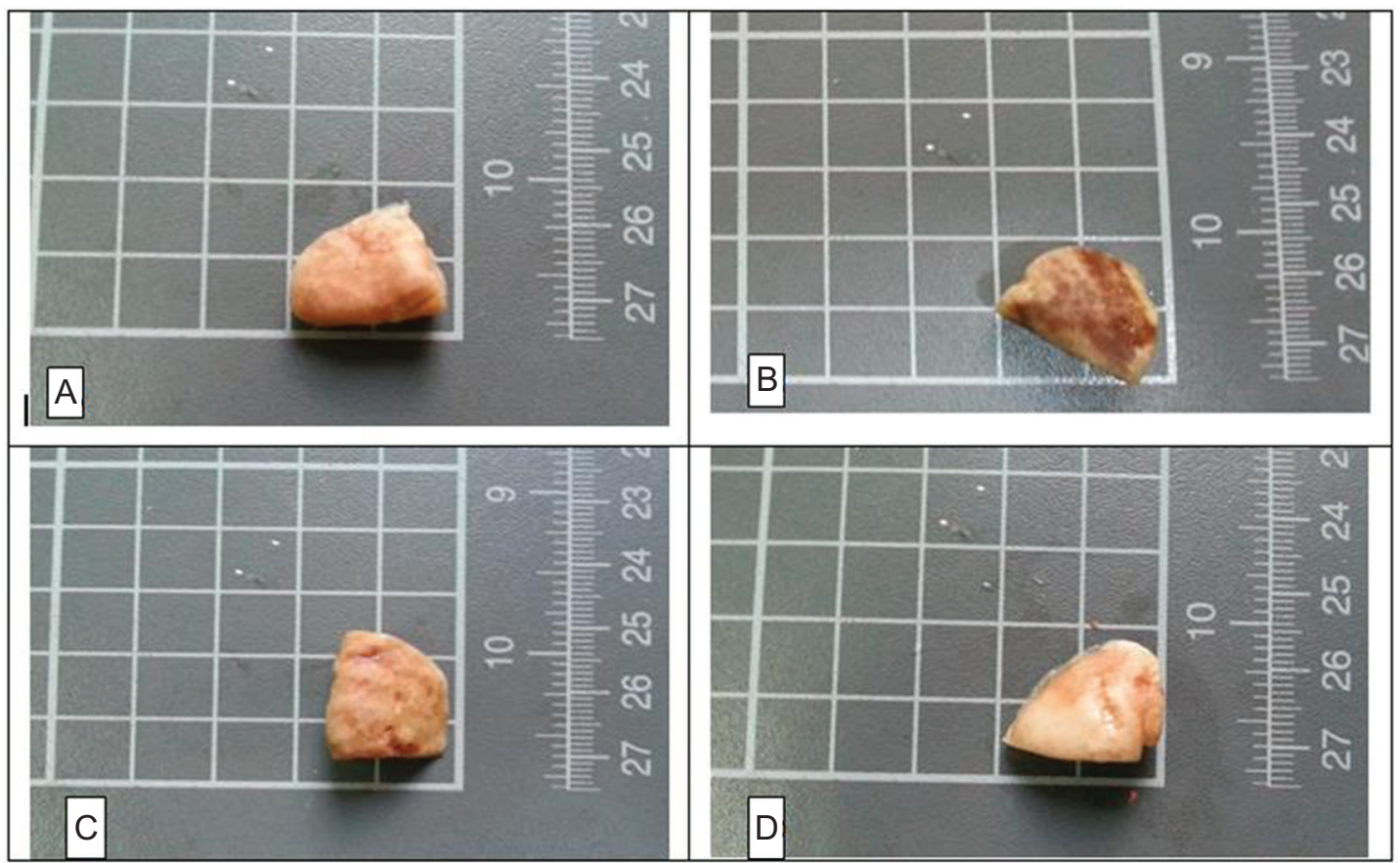

Figure 1 The macroscopic images of the groups' lung tissues. (A) Control group; (B) Rocuronium only group; (C) Sugammadex only group; (D) Combined group.

Table 1 The comparison of serum immunoglobulin $\mathrm{E}$ and C-reactive protein values of the groups.

\begin{tabular}{|c|c|c|c|c|c|c|c|c|c|c|}
\hline & \multirow[t]{2}{*}{ Group C } & \multirow[t]{2}{*}{ Group R } & \multirow[t]{2}{*}{ Group S } & \multirow[t]{2}{*}{ Group RS } & \multicolumn{6}{|c|}{$\mathrm{P}$} \\
\hline & & & & & All & $C-R$ & C-S & C-RS & R-RS & S-RS \\
\hline $\operatorname{lgE}(\mu \mathrm{g} / \mathrm{mL})$ & $19.37 \pm 1.02$ & $29.14 \pm 1.35$ & $23.73 \pm 1.07$ & $22.02 \pm 1.05$ & $<0.05^{\mathrm{a}}$ & $<0.01^{b}$ & $<0.01^{\mathrm{b}}$ & $<0.01^{b}$ & $<0.01^{b}$ & $<0.01^{b}$ \\
\hline CRP (ng/mL) & $4.43 \pm 0.39$ & $9.71 \pm 0.74$ & $6.94 \pm 0.43$ & $5.34 \pm 0.52$ & $<0.05^{\mathrm{a}}$ & $<0.01^{b}$ & $<0.01^{b}$ & $<0.01^{b}$ & $<0.01^{b}$ & $<0.01^{b}$ \\
\hline
\end{tabular}

The values were stated as mean \pm SD. $N=7$ for each group.

a Kruskal-Wallis test; ' ${ }^{\mathrm{M}}$ Mann-Whitney $\mathrm{U}$ test

\section{Toluidine blue staining}

Total mast cell number was significantly higher in Group R than the other groups. In Group R and Group S, the total mast cell number was greater than Group C. In Group RS, although total mast cell number was significantly lower than that of Group R and Group S, it was significantly higher than that of Group C (Figure 3).

\section{Immunohistochemistry (tryptase staining)}

Immunohistochemically, when tryptase reactivity of the sections that belonged to lung tissues was observed, it was seen that the number and the distribution of the mast cells showed parallelism with the toluidine staining. The number of tryptase-positive mast cells in Group R was significantly higher than the other groups. In Group RS, while tryptase-positive mast cell number was significantly lower compared with that of Group R and Group S, it was significantly higher than that of Group C (Table 2, Figure 4).

\section{Discussion}

In this study, we found that the increase in IgE and CRP levels (in serum), peribronchial and alveolar septal lymphocytic infiltration, mast cells and tryptase positive mast cells numbers due to rocuronium in rat lungs was decreased with sugammadex. Also, we demonstrated that all the above-mentioned changes in the lungs and sera of rats given rocuronium and sugammadex occur less than those that were given only rocuronium or sugammadex.

Immunoglobulin $\mathrm{E}$ is a protein that can increase during allergic diseases, whereas CRP is a protein that increases during inflammation. There was a significant increase in serum IgE and CRP levels in all groups that received rocuronium and/or sugammadex compared with the control in our study. This result shows that both drugs can induce allergy and inflammation. Two other studies investigating the effect of sugammadex on changes made by rocuronium have evaluated AST/ALT ${ }^{18}$ and glucose/calcium. ${ }^{19}$ 


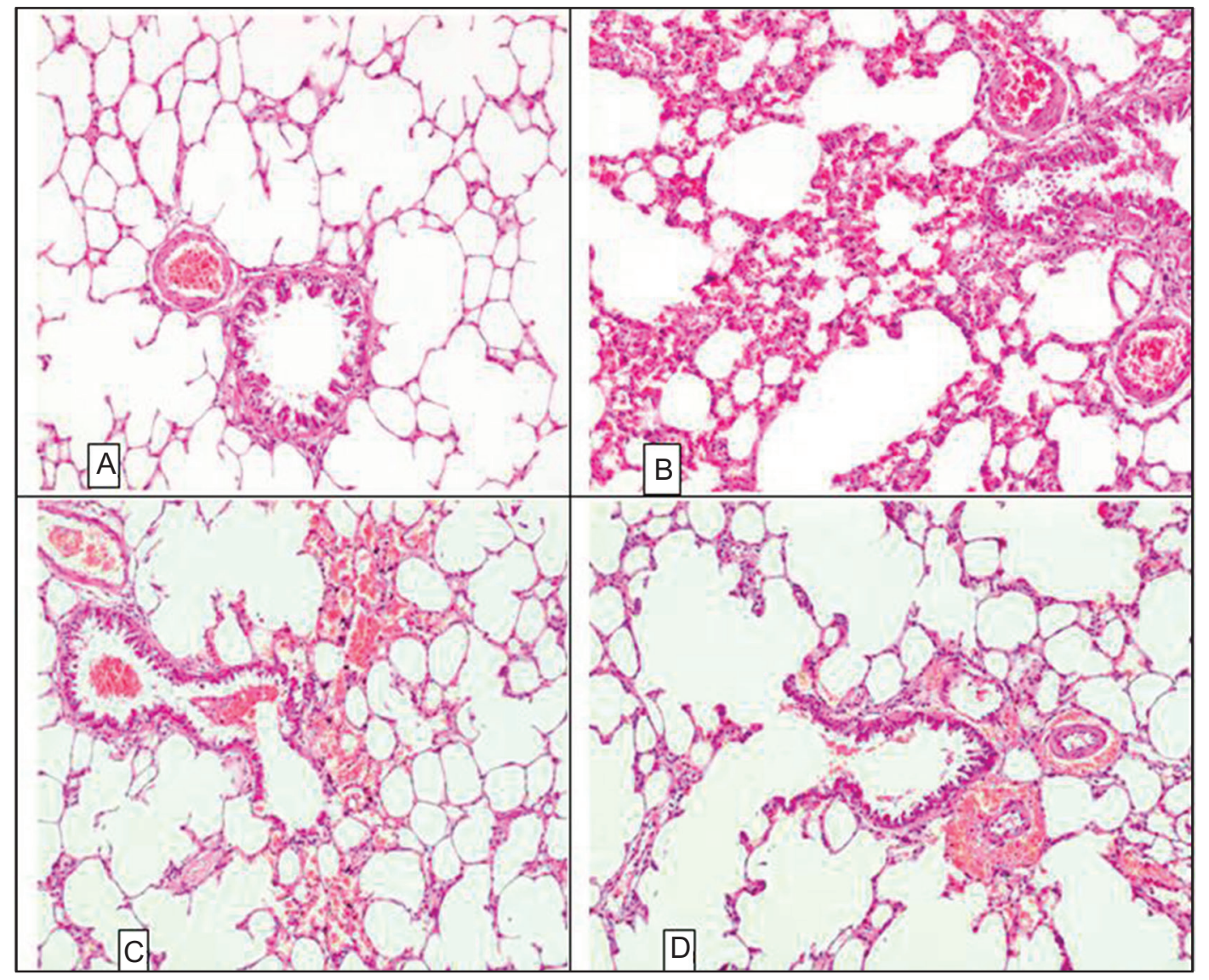

Figure 2 The H\&E staining of the lung sections that belong to the groups of rats (20X). (A) Control group; normal lung tissues is seen; (B) Rocuronium group; the peribronchial and septal lymphocytic infiltration increased along with the thickening of the alveolar membranes and rise in bleeding sites even more; (C) Sugammadex group; thickening of the alveolar membranes in some areas, peribronchial and septal lymphocytic infiltration is seen. Also, it is observed that bleeding sites occurred in some areas; (D) Combined group; the lymphocytic infiltration, septal thickening and the bleeding reduced compared with the Group $\mathrm{S}$ and particularly to the Group R and neared the control group.

In this study, when the lung sections of sugammadex-treated rats were examined under light microscopy, peribronchial and alveolar septal lymphocyte infiltration was observed with slight thickening of the alveolar walls in some regions and haemorrhagic foci were observed. When only the rocuronium-treated rats were examined, it was found that the bleeding foci were also proliferated. When the lung sections of rats given sugammadex after rocuronium application were examined, it was seen that lymphocyte infiltration, septal thickening and haemorrhage decreased and approached the control. These light microscopy and toluidine staining results obtained from lung tissue are consistent with the results obtained by Tomak et al. ${ }^{19}$ from rat liver and Kalkan et al. ${ }^{19}$ from rat pancreas. This result shows that sugammadex suppresses the inflammatory response made by rocuronium.

Mast cells are key initiators and modulators of allergic, anaphylactic and other inflammatory reactions, by induction of vasodilation, promotion of vascular permeability, recruitment of inflammatory cells, facilitation of adaptive immune responses, modulation of angiogenesis and fibrosis. Mast cells were primarily known as the main effector cells in type-I allergic reactions and diseases, for example, allergic rhino-conjunctivitis, urticaria and anaphylaxis. Mast cells are found more intensely in areas where the body opens to external environments such as the skin, respiratory and gastrointestinal tracts. They interact with the external environment and are predominantly located in close proximity of blood vessels and sensory nerves. Mast cells accumulate at inflammatory sites associated with atopy. ${ }^{20}$ The most important feature of mast cells is that they contain a large number of granules in their cytoplasm. There is a heterogeneity in mast cells relating to whether the granule proteases are chymase or tryptase. The granules of mast cells in the mucosa are rich in tryptase and play a role in acute inflammatory events. These granules are stained metachromically with dyes such as toluidine blue, alcien blue and azure A. Immediately after the acute phase, toluidine blue positive mast cells accumulate in the epithelium of the trachea and in the lung parenchyma. ${ }^{21,22}$ The number and the distribution of the mast cells showed parallelism with the toluidine staining (tryptase reactivity) in this study. The highest total mast cells count and tryptase-positive 


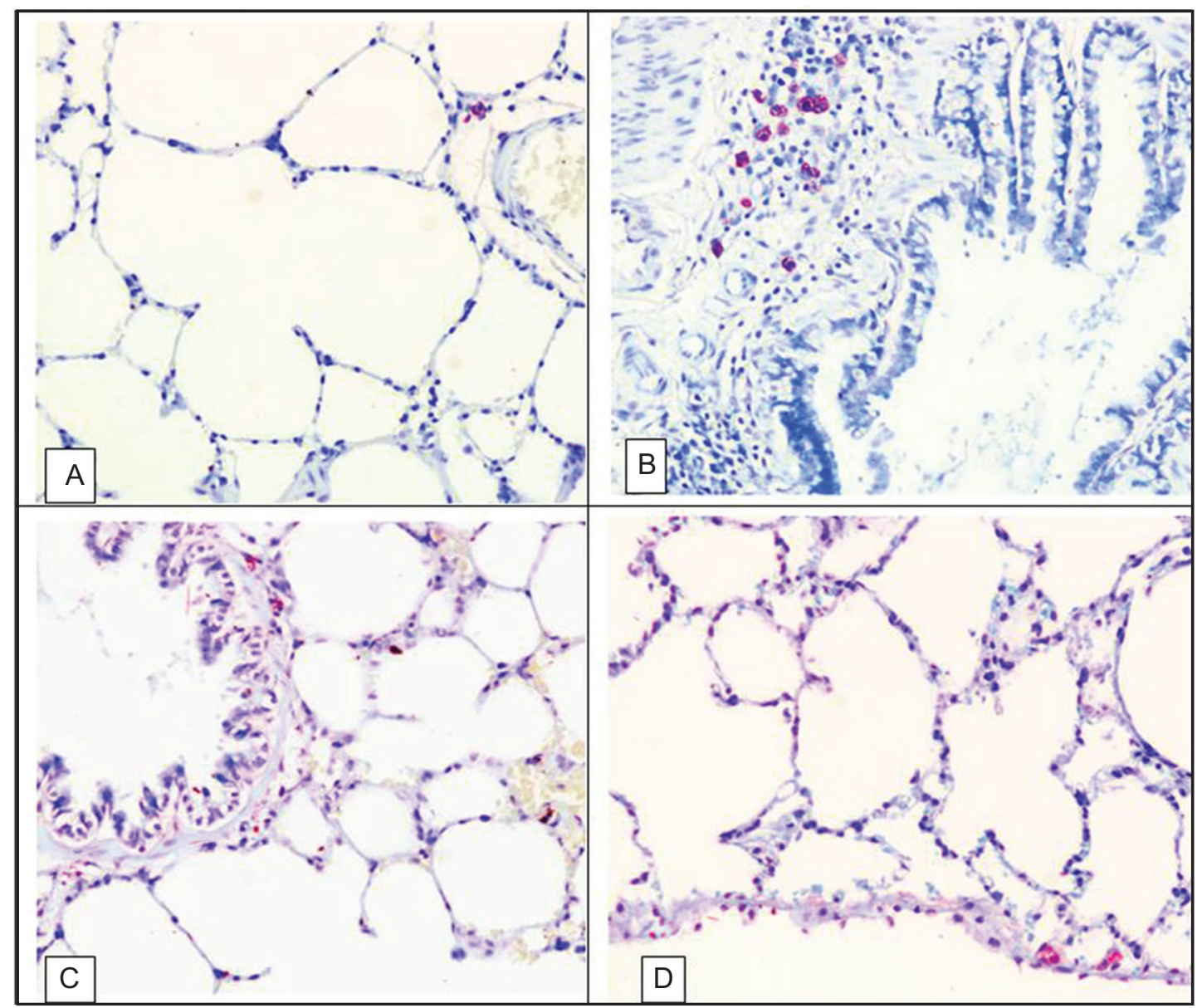

Figure 3 The toluidine blue staining of the lung sections that belong to the groups of rats (20X). (A) Control group: there was only a few mast cells in peribronchial and the alveolar membranes; (B) Rocuronium only group: the number of the mast cells was excessively increased in alveolar membranes, peribronchial and subpleural areas; (C) Sugammadex only group: the number of the mast cells was increased in alveolar membranes, peribronchial and subpleural areas; (D) Combined group: the number of the mast cells decreased and neared the control group when compared to the only groups.

Table 2 The Comparison of mast cells and tryptase-positive mast cells counts of the groups.

\begin{tabular}{|c|c|c|c|c|c|c|c|c|c|c|}
\hline & \multirow[t]{2}{*}{ Group C } & \multirow[t]{2}{*}{ Group R } & \multirow[t]{2}{*}{ Group S } & \multirow[t]{2}{*}{ Group RS } & \multicolumn{6}{|c|}{$P$} \\
\hline & & & & & All & $C-R$ & C-S & C-RS & R-RS & S-RS \\
\hline Toluidine blue & $18.92 \pm 1.3$ & $35.26 \pm 3.1$ & $27.78 \pm 2.5$ & $22.78 \pm 1.8$ & $<0.05^{\mathrm{a}}$ & $<0.01^{b}$ & $<0.01^{\mathrm{b}}$ & $<0.01^{b}$ & $<0.01^{\mathrm{b}}$ & $<0.01^{\mathrm{b}}$ \\
\hline Tryptase & $24.82 \pm 2.1$ & $45.2 \pm 3.6$ & $34.72 \pm 3.2$ & $28.2 \pm 2.6$ & $<0.05^{\mathrm{a}}$ & $<0.01^{b}$ & $<0.01^{b}$ & $<0.01^{b}$ & $<0.01^{b}$ & $<0.01^{b}$ \\
\hline
\end{tabular}

The values were stated as mean \pm SD. $N=7$ for each group.

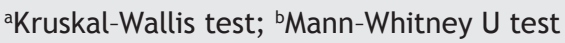

mast cells count in this study were found in rats receiving rocuronium. The number of total mast cells and tryptasepositive mast cells were higher in rats receiving sugammadex compared with that of the control. This result shows that sugammadex can also cause allergic reactions. As mentioned earlier, cases of anaphylaxis due to sugammadex have been reported in the literature. ${ }^{14}$ The number of total mast cell and tryptase-positive mast cell in those given with rocuronium and sugammadex were lower than those that were given only rocuronium or sugammadex. This result shows that sugamamdex can be used in the treatment of rocuronium-related allergic reactions. Similar results were found in the study of Tomak et al. ${ }^{18}$ and Kalkan et al. ${ }^{19}$ Sugammadex reduces the increase and degranulation caused by rocuronium in mast cells of liver and pancreas and shows the same effect on lung mast cells. Case reports compatible with this result are also available in the literature. ${ }^{11-13}$ 


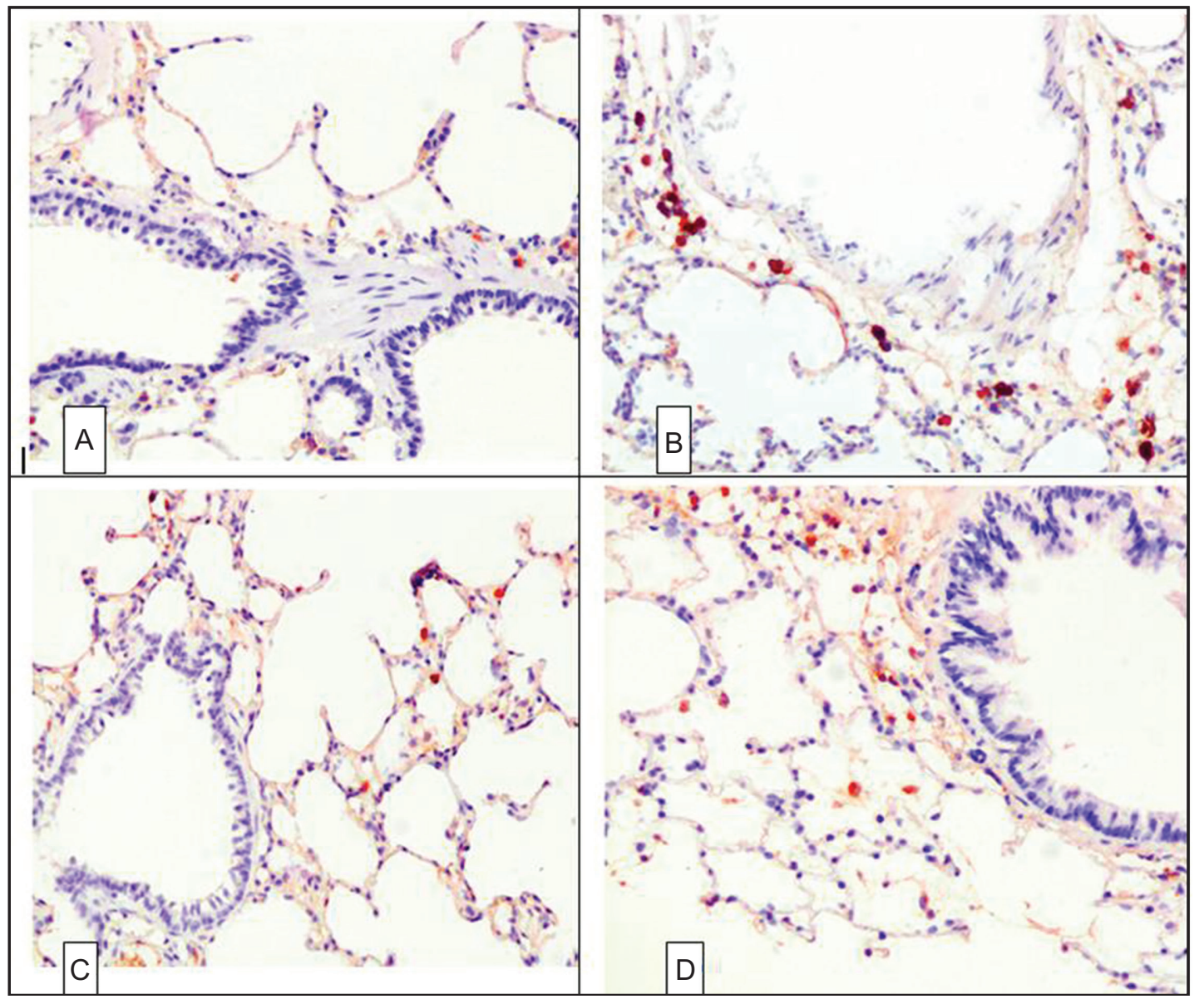

Figure 4. The tryptase staining of the lung sections that belong to the groups of rats (20X). (A) Control group; the number of the mast cells was quite scarce in peribronchial and subpleural areas; (B) Rocuronium only group; the number of the mast cells increased extremely, and mast cells were degranulated and showed tryptase immunoreactivity even in the extracellular area; (C) Sugammadex only group; the number of the mast cells slightly increased; (D) Combined group; the number of the mast cells that showed tryptase immunoreactivity reduced and the distribution of them became scarce.

In the literature, there are two articles investigating the effects of sugammadex on the reaction developed due to rocuronium. One of these is an experimental study, where the effect of rocuronium and sugammadex on mast cells in the rat liver portal area was investigated and a significant increase was observed in total and active (tryptase positive) mast cells in the rocuronium treated group compared with that of all other groups. In groups where rocuronium was administered concomitantly with sugammadex, a significant decrease was observed dependent on sugammadex dose in mast cells. It was observed that mast cells were significantly increased in the sugammadex treated group compared with that in the control group. These results have shown that not only sugammadex reduces dose-dependent activation of rocuronium-induced mast cells, but also causes an increase in mast cells, although it is less than rocuronium..$^{18}$ Another study investigated the effect of sugammadex on pancreatic changes due to rocuronium; it was found that the number of mast cells was higher and the distribution rate of the granules and nuclear changes were higher in the rocuronium-treated group compared with that of the other groups. ${ }^{19}$ The authors concluded that sugammadex may have a preventive effect on mobilization and morphological changes caused by rocuronium in the mast cells of the pancreas..$^{18,19}$ These results are consistent with the results of our study.

Although the liver and the pancreas are the organs that are possibly affected by anaphylactic reactions, the lungs are affected in most cases. In addition, rocuronium and sugammadex can only be in reactions affecting the lungs. ${ }^{12,23}$ For these reasons, we think that the results of this study are more important.

In this study, we found that sugammadex alleviates allergic changes due to rocuronium in the lungs. Although Tomak et al. ${ }^{18}$ and Kalkan et al. ${ }^{19}$ have similar results, in-vitro and in-vivo human models of anaphylaxis have not been able to demonstrate immunologically mediated attenuation of established anaphylaxis. ${ }^{24,25}$ In addition, a case that has not improved with administration of sugammadex in rocuronium-induced anaphylaxis has been reported. ${ }^{26}$ But the sugammadex dose used in this case is low $(2.7 \mathrm{mg} / \mathrm{kg})$. Although Barthel et al. ${ }^{27}$ recommend the dose of $16 \mathrm{mg} / \mathrm{kg}$ for sugammadex to be effective, there are patients who received clinical response with a lower dose in the literature. ${ }^{28}$ The dose of sugammadex in the treatment of rocuronium-induced 
anaphylaxis is unclear. In recent years, while there has been no reaction to rocuronium or sugammadex, it has been shown that an allergic reaction may develop against rocuronium-sugammadex inclusion complex. Sugammadex and rocuronium bind in a 1:1 molar ratio so in the preparation of the inclusion complex, quantities reflecting the stoichiometric ratio of the compounds should be used. The molecular mass of sugammadex is $2178 \mathrm{~g} / \mathrm{mol}$ and that of rocronium bromide $609.7 \mathrm{~g} /$ $\mathrm{mol}$, so $3.57 \mathrm{~g}$ of sugammadex binds $1 \mathrm{~g}$ of rocuronium bromide. ${ }^{29}$ Ebo et al. ${ }^{17}$ suggested that while rocuroniumsugammadex inclusion complex is formed, it becomes allergenic due to the change in the structural configuration of sugammadex.

\section{Conclusions}

As a result, we found that allergic changes in rat lungs due to rocuronium decreased with sugammadex in our study, These results may be evidence that sugammadex can be used to treat anaphylaxis developing with rocuronium. The case reports mentioned above, where rocuronium-induced anaphylaxis is treated with sugammadex, are clinical supports of these results. We concluded that sugammadex may be given to a patient with hypersensitivity reactions if there is a high index of suspicion that rocuronium being the causative agent and conventional treatment is failing. But it is very important to bear in mind that sugammadex is not a blameless drug and it can also cause anaphylaxis. In addition, it should be kept in mind that anaphylaxis may develop due to the rocuronium-sugammadex inclusion complex.

\section{Acknowledgments}

This study was supported in part by grants from Istanbul Medeniyet University, Scientific Research Projects Office (BAP) (TTU-2013-478).

\section{References}

1. Michavila Gomez AV, Belver Gonzalez MT, Alvarez NC, Giner Muñoz MT, Hernando Sastre V, Porto Arceo JA, Induráin BV. Drug allergy work group of the Spanish Society of Paediatric Allergy, Immunology (SEICAP) perioperative anaphylactic reactions: review and procedure protocol in paediatrics. Allergol Immunopathol (Madr). 2015;43(2):203-14. https://doi. org/10.1016/j.aller.2013.07.012.

2. Kemp HI, Cook TM, Thomas M, Harper NJN. UK anaesthetists' perspectives and experiences of severe perioperative anaphylaxis: NAP6 baseline survey. $\mathrm{Br} \mathrm{J}$ Anaesth. 2017;119(1):132-9. https://doi.org/10.1093/bja/aex124

3. Savic LC, Kaura V, Yusaf M, Hammond-Jones AM, Jackson R, Howell S, et al. Anaesthetic Audit and Research Matrix of Yorkshire. Incidence of suspected perioperative anaphylaxis: A multicenter snapshot study. J Allergy Clin Immunol Pract. 2015;3(3):454-5. https://doi.org/10.1016/j.jaip.2014.12.016

4. Dong SW, Mertes PM, Petitpain N, Hasdenteufel F, Malinovsky JM. GERAP. Hypersensitivity reactions during anesthesia. Results from the ninth French survey (2005-2007). Minerva Anestesiol. 2012;78(8):868-78.
5. Florvaag $E$, Johansson SG, Oman $H$, Venemalm $L$, Degerbeck F, Dybendal T, et al. Prevalence of IgE antibodies to morphine. Relation to the high and low incidences of NMBA anaphylaxis in Norway and Sweden, respectively. Acta Anaesthesiol Scand. 2005;49(4):437-44. https://doi. org/10.1111/j.1399-6576.2004.00591.x

6. Mirakhur RK. Safety aspects of non-depolarizing neuromuscular blocking agents with special reference to rocuronium bromide. Eur J Anaesthesiol Suppl. 1994;9:133-40.

7. Bevan DR. Newer neuromuscular blocking agents. Pharmacol Toxicol. 1994;74(1):3-9. https://doi.org/10.1111/j. 1600-0773.1994.tb01065.x

8. Sadleir PH, Clarke RC, Bunning DL, Platt PR. Anaphylaxis to neuromuscular blocking drugs: incidence and cross-reactivity in Western Australia from 2002 to 2011. Br J Anaesth. 2013;110(6):981-7. https://doi.org/10.1093/bja/aes506

9. Schaller SJ, Fink H. Sugammadex as a reversal agent for neuromuscular block: an evidence-based review. Core Evid. 2013;8:57-67. https://doi.org/10.2147/CE.S35675

10. Czarnetzki C, Tassonyi E, Lysakowski C, Elia N, Tramèr MR. Efficacy of sugammadex for the reversal of moderate and deep rocuronium-induced neuromuscular block in patients pretreated with intravenous magnesium: a randomized controlled trial. Anesthesiology. 2014;121(1):59-67. https://doi. org/10.1097/ALN.0000000000000204

11. McDonnell NJ, Pavy TJ, Green LK, Platt PR. Sugammadex in the management of rocuronium-induced anaphylaxis. $\mathrm{Br} \mathrm{J}$ Anaesth. 2011;106(2):199-201. https://doi.org/10.1093/bja/aeq366

12. De La Cruz I, Errando C, Calaforra S. Treatment of anaphylaxis to rocuronium with sugammadex: a case report with bronchospasm as the only symptom. Turk J Anaesthesiol Reanim. 2019;47(1):69-72. https://doi.org/10.5152/TJAR.2019.21298

13. Kawano T, Tamura T, Hamaguchi M, Yatabe T, Yamashita K, Yokoyama M. Successful management of rocuronium-induced anaphylactic reactions with sugammadex: a case report. J Clin Anesth. 2012;24(1):62-4. https://doi.org/10.1016/j. jclinane.2011.04.015

14. Takazawa T, Tomita Y, Yoshida N, Tomioka A, Horiuchi T, Nagata C, Orihara $M$, et al. Three suspected cases of sugammadex-induced anaphylactic shock. BMC Anesthesiol. 2014;14:92. https://doi.org/10.1186/1471-2253-14-92

15. Min KC, Woo T, Assaid C, McCrea J, Gurner DM, Sisk CM, et al. Incidence of hypersensitivity and anaphylaxis with sugammadex. J Clin Anesth. 2018;47:67-73.https://doi.org/10.1016/j. jclinane.2018.03.018

16. Ho G, Clarke RC, Sadleir PH, Platt PR. The first case report of anaphylaxis caused by the inclusion complex of rocuronium and sugammadex. A A Case Rep. 20161;7(9):190-2. https://doi. org/10.1213/XAA.0000000000000382

17. Ebo DG, Baldo BA, Van Gasse AL, Mertens C, Elst J, Sermeus L, et al. Anaphylaxis to sugammadex-rocuronium inclusion complex: an IgE-mediated reaction due to allergenic changes at the sugammadex primary rim. J Allergy Clin Immunol Pract. 2020;8(4):1410-5. https://doi.org/10.1016/j.jaip.2019.11.018.

18. Tomak Y, Yılmaz A, Bostan H, Tümkaya L, Altuner D, Kalkan $\mathrm{Y}$, et al. Effects of sugammadex and rocuronium mast cell number and degranulation in rat liver. Anaesthesia. 2012;67(10):11014. https://doi.org/10.1111/j.1365-2044.2012.07264.X

19. Kalkan Y, Tumkaya L, Bostan H, Tomak Y, Altuner D, Yilmaz A, et al. Effect of sugammadex on rocuronium induced changes in pancreatic mast cells. Toxicol Ind Health. 2015;31(8):73846. https://doi.org/10.1177/0748233713484654

20. Elieh Ali Komi D, Wöhrl S, Bielory L. Mast cell biology at molecular level: a comprehensive review. Clin Rev Allergy Immunol. 2020;58(3):342-65. https://doi.org/10.1007/s12016-019-08769-2.

21. McNeil HP, Gotis-Graham I. Human mast cell subsets--distinct functions in inflammation? Inflamm Res. 2000;49(1):3-7. https://doi.org/10.1007/PL00012386 
22. Schwartz LB. Mast cells and their role in urticaria. J Am Acad Dermatol. 1991;25:190-203; 203-4. https://doi.org/10.1016/ S0190-9622(08)80468-9

23. Baronos S, Selvaraj BJ, Liang M, Ahmed K, Yarmush J. Sugammadex-induced bronchospasm during desflurane anaesthesia. Br J Anaesth. 2019;123(1):e155-6. https://doi. org/10.1016/j.bja.2019.04.001

24. Clarke RC, Sadleir PH, Platt PR. The role of sugammadex in the development and modification of an allergic response to rocuronium: evidence from a cutaneous model. Anaesthesia. 2012;67(3):266-73. https://doi. org $/ 10.1111 / \mathrm{j} .1365-2044.2011 .06995 . x$

25. Leysen J, Bridts CH, De Clerck LS, Ebo DG. Rocuronium-induced anaphylaxis is probably not mitigated by sugammadex: evidence from an in vitro experiment. Anaesthesia. 2011;66(6):5267. https://doi.org/10.1111/j.1365-2044.2011.06729.x
26. Hakozaki T, Murakawa M. Rocuronium-induced anaphylaxis not improved by low dose sugammadex: a case report. Anaesth Intensive Care. 2016;44(4):522. https://doi. org / $10.1177 / 0310057 X 1604400411$

27. Barthel F, Stojeba N, Lyons G, Biermann C, Diemunsch P. Sugammadex in rocuroniumanaphylaxis: dosematters. $\mathrm{Br}$ J Anaesth. 2012;109(4):646-7. https://doi.org/10.1093/bja/ aes332

28. Platt PR, Clarke RC, Johnson GH, Sadleir PH. Efficacy of sugammadex in rocuronium-induced or antibiotic-induced anaphylaxis. A case-control study. Anaesthesia. 2015;70(11):12647. https://doi.org/10.1111/anae.13178

29. Baldo BA. Anaphylaxis caused by sugammadex- rocuronium inclusion complex: What is the basis of the allergenic recognition? J Clin Anesth. 2019;54:48-9. https://doi.org/10.1016/j. jclinane.2018.10.017 